\title{
Research on the Development of Logistics Mode of Characteristic Agricultural Products in Guangdong Province Under the Background of "Internet +"
}

\author{
Yan Fang ${ }^{1, *}$ \\ ${ }^{1}$ Business Administration, Heyuan Polytechnic School, Heyuan, Guangdong, 517000,China \\ *Corresponding author's e-mail: 71719330@qq.com
}

\begin{abstract}
In order to promote the development of regional characteristic agricultural products logistics, this paper analyzes the characteristics of various current characteristic agricultural products logistics models, and makes empirical analysis based on the actual situation of the development of regional characteristic agricultural products logistics in Guangdong, through factor analysis and cluster analysis,according to the characteristics of the development of agricultural products in Guangdong, we classify them, and select the logistics development mode suitable for the region according to their characteristic.The"Internet+"concept is integrated into various logistics development modes so as to optimize the current model to better promote the development of regional characteristic agricultural products industry.

Keywords: Guangdong Province, characteristic agricultural products, logistics mode, factor analysis, cluster analysis
\end{abstract}

\section{INTRODUCTION}

On July 29, 2019, the Department of agriculture and rural areas of Guangdong Province issued the confirmation of 46 priority areas of characteristic agricultural products of Guangdong $^{[1]}$.The development of characteristic agricultural products is an important measure to promote agricultural supply-side structural reforms, promote agricultural green development, drive traditional agricultural areas and poverty-stricken areas to get rid of poverty and become rich, and improve the quality and efficiency of agricultural products and competitiveness.An efficient logistics system is critical to the development of specialty agricultural products, which can ensure that various types of characteristic agricultural products are delivered to consumers in a fast, high-quality and effective manner, reduce the consumption of characteristic agricultural products, effectively improve the competitiveness of specialty agricultural products, increase farmers 'income, and meet the needs of consumers for characteristic agricultural products.However, most of the characteristic agricultural products in Guangdong Province still adopt the original distribution stage of spot trading through the agricultural trade market, which leads to the long circulation cycle of many characteristic agricultural products, the problems of perishable and low purchase price, the high transaction cost and logistics cost, the damage of product quality, and the impact on Farmers' income and the reputation of characteristic agricultural products. The choice of reasonable logistics mode is crucial to the development of characteristic agricultural products and the improvement of farmers' income and product quality.

\section{Analysis on logistics mode of characteristic agricultural products in Guangdong province}

Based on a survey of the current characteristics of agricultural product logistics in Guangdong Province, there are four types of Guangdong's characteristic agricultural product logistics models.

\subsection{A self-operated logistics model led by characteristic agricultural product manufacturing enterprises.}

This model is dominated by production or processing enterprises, which carry out all kinds of logistics operations from production to sales of characteristic agricultural products through self-built warehouses and fleets.Adopting this logistics mode requires enterprises has strong capital and technology strength, strong competitiveness, strong operation and management ability, and strong management and supervision ability for upstream and downstream enterprises[2].The enterprises adopting this mode can master the upstream and downstream product information, and coordinate the operation of the upstream and downstream enterprises in the supply chain. 


\subsection{Third-party logistics model led by professional logistics companies.}

This mode takes the third-party logistics enterprises as the core, and provides cross regional, cross industry and other comprehensive logistics services for the production, storage, transportation, circulation and processing of characteristic agricultural products.For the third-party logistics enterprises, they need to have professional storage places, circulation processing equipment, vehicles and information management system for agricultural products logistics, so as to ensure the quality and speed of characteristic agricultural products in the logistics process.

\subsection{Logistics mode with wholesale market as the core}

The logistics model is based on the wholesale market where the product is produced or sold. The producers of specialty agricultural products sell products through the wholesale market, and sales enterprises at all levels obtain products through the wholesale market to complete the final sales. The wholesale market links production, processing, circulation and sales.This mode is the most common logistics mode in the process of collecting and distributing special agricultural products in Guangdong Province. It is also the most selected logistics mode by many small and medium producers and retail terminals. It is simple to operate and easy to implement. It does not have high requirements for producers and retail terminals, but there is a long logistics chain. , High logistics costs and high losses.

\subsection{Supply chain alliance logistics model with large buyers as the mainstay.}

This model takes large chain supermarkets as the core and directly signs contracts with farmers or rural cooperatives to realize the direct transfer of products from the origin to the supermarket shelves, reducing intermediate links, reducing transaction costs, increasing farmers' income, and lowering sales prices.However, this model requires a sales company to have a professional cold-chain distribution center to complete all the storage, distribution, and transportation processes of the product from the production end to the shelf [5], which is highly required for chain enterprises.

\section{3. "INTERNET +" PERFORMANCE EVALUATION OF GUNGDONG'S CHARACTERISTIC AGRICULTURAL PRODUCTS LOGISTICS}

\subsection{Research methods}

In order to understand the logistics performance of characteristic agricultural products in various regions of Guangdong Province under the Internet + background, factor analysis and cluster analysis were selected to evaluate the logistics performance of the 21 characteristic cities in Guangdong province.Factor analysis can reduce the dimension of some complicated variables to several common factors, quickly find out the main factors that affect the logistics performance of Guangdong Province's characteristic agricultural products, and evaluate the logistics level of each region's characteristic agricultural products. The cluster analysis classifies different samples, finds the common points of each category, and provides the analysis basis for selecting the appropriate logistics mode. The software selected in this paper is SPSS19.0.

\subsection{Selection of research indicators}

By referring to the literature on the research of agricultural products logistics mode, and based on the principles of scientificity, availability, and measurability of evaluation indicators, 10 secondary indicators including logistics demand, logistics scale and development environment, are selected for research, as shown in Table 1.The data selected in the study are from the statistical yearbook of Guangdong Province in 2019.

Table 1.Evaluation index system of regional characteristic agricultural products logistics

\begin{tabular}{|c|c|c|c|}
\hline First-level indicators & Secondary indicators & Unit & Indicator code \\
\hline \multirow{4}{*}{ Logistics demand } & Output of main agricultural products & Ten thousand tons & $\mathrm{x}_{1}$ \\
\cline { 2 - 4 } & $\begin{array}{c}\text { Agriculture, forestry, fishery and animal husbandry } \\
\text { output value }\end{array}$ & Billion yuan & $\mathrm{x}_{2}$ \\
\cline { 2 - 4 } & Number of urban population & ten thousand people & $\mathrm{x}_{3}$ \\
\cline { 2 - 4 } & The total retail sales of social consumer goods & Ten thousand yuan & $\mathrm{x}_{4}$ \\
\hline \multirow{3}{*}{\begin{tabular}{c} 
Logistics scale \\
\cline { 2 - 4 }
\end{tabular}} & Proportion of tertiary industry to GDP & Ten thousand tons & $\mathrm{x}_{5}$ \\
\hline \multirow{3}{*}{$\begin{array}{c}\text { Development } \\
\text { Environment }\end{array}$} & Highway mileage & Each & $\mathrm{x} 6$ \\
\cline { 2 - 4 } & Total Post and Telecommunications Services & KM & $\mathrm{x} 8$ \\
\cline { 2 - 4 } & Number of civilian trucks & Million & $\mathrm{x}_{9}$ \\
\hline
\end{tabular}


KMO and Bartlett tests were performed on the data by SPSS19.0 software. $\mathrm{KMO}=0.679\rangle 0.6$, and the sig. Value of Bartlett's spherical test is $0<0.05$, indicating that each index is suitable for factor analysis. The test results are shown in Table 2.

Table $2 \mathrm{KMO}$ and Bartlett's test

\begin{tabular}{|c|c|c|}
\hline \multicolumn{2}{|c|}{ Kaiser-Meyer-Olkin measure of sample adequacy } & .679 \\
\hline \multirow{3}{*}{ Bartlett's sphericity test } & Approximate chi-square & 350.891 \\
\cline { 2 - 3 } & df & 45 \\
\cline { 2 - 3 } & Sig. & .000 \\
\hline
\end{tabular}

\subsubsection{Extract common factor}

obtained. It can be seen from the table that the cumulative variance contribution rate of the first two principal components reaches $86.078 \%$, which retains sufficient original information and has strong representativeness. Therefore, these two common factors are extracted.

Using principal component analysis, common factors are extracted according to the size of eigenvalues and the cumulative contribution rate of variance, and table 3 is

Table 3 Total variance explained

\begin{tabular}{|c|c|c|c|c|c|c|c|c|c|}
\hline \multirow{2}{*}{ Ingredients } & \multicolumn{3}{|c|}{ Initial eigenvalue } & \multicolumn{3}{c|}{ Extract square sum load } & \multicolumn{3}{c|}{ Rotate square sum load } \\
\cline { 2 - 10 } & total & variance \% & Cumulative \% & total & variance \% & Cumulative\% & total & variance \% & Cumulative\% \\
\hline 1 & 6.183 & 61.832 & 61.832 & 6.183 & 61.832 & 61.832 & 5.996 & 59.958 & 59.958 \\
\hline 2 & 2.425 & 24.246 & 86.078 & 2.425 & 24.246 & 86.078 & 2.612 & 26.119 & 86.078 \\
\hline
\end{tabular}

Extraction method: principal component analysis.

\subsubsection{Analysis of Factor Naming and Economic Meaning}

The factor rotation of the initial load matrix is carried out by the method of maximum variance orthogonal rotation, so that the factor has the named explanation, and the results are shown in Table 4.It can be seen that the first public factor $\left(\mathrm{F}_{1}\right)$ has a high load on the number of urban population $\left(\mathrm{x}_{3}\right)$, the total retail sales of social consumption $\left(\mathrm{x}_{4}\right)$, the turnover of goods ( $\left.\mathrm{x}_{5}\right)$, the proportion of the tertiary industry in GDP $\left(\mathrm{x}_{6}\right)$, the total volume of post and
Telecommunications business $\left(\mathrm{x}_{8}\right)$, the volume of civil trucks $\left(\mathrm{x}_{9}\right)$, and the mobile phone $\left(\mathrm{X}_{10}\right)$. These seven factors mainly reflect the development level of regional economy and logistics industry, so It can be named regional economic development factor; The second public factor $\left(F_{2}\right)$ has a high load on the main agricultural products $\left(\mathrm{x}_{1}\right)$, the main agricultural, forestry, fish and animal husbandry output value $\left(\mathrm{x}_{2}\right)$, and the highway mileage $\left(\mathrm{x}_{7}\right)$. These two three indicators mainly reflect the logistics demand of characteristic agricultural products, which can be named as the logistics demand factor.

Table 4 component score coefficient matrix

\begin{tabular}{|l|c|c|c|c|c|c|c|c|c|c|c|c|}
\hline \multicolumn{2}{|c|}{ indicators } & $\mathrm{X}_{1}$ & $\mathrm{X}_{2}$ & $\mathrm{X}_{3}$ & $\mathrm{X}_{4}$ & $\mathrm{X}_{5}$ & $\mathrm{X}_{6}$ & $\mathrm{X}_{7}$ & $\mathrm{X}_{8}$ & $\mathrm{X}_{9}$ & $\mathrm{X}_{10}$ \\
\hline \multirow{2}{*}{$\begin{array}{l}\text { Component score } \\
\text { coefficient matrix }\end{array}$} & Ingredients & $\mathrm{F}_{1}$ & 0.054 & 0.042 & 0.155 & 0.169 & 0.152 & 0.145 & 0.012 & 0.156 & 0.152 & 0.159 \\
\cline { 2 - 12 } & $\mathrm{F}_{2}$ & 0.366 & 0.368 & -0.023 & 0.03 & 0.102 & 0.073 & 0.333 & -0.028 & -0.034 & -0.017 \\
\hline
\end{tabular}

\subsubsection{Factor score calculation and comprehensive ranking.}

In order to calculate the logistics level of characteristic agricultural products in 21 cities of Guangdong Province, the proportion of variance contribution rate obtained by two common factors in the cumulative contribution rate is used as the weight for weighted calculation, and the calculation formula of comprehensive score is obtained. The calculation formula of each common factor score is as follows:

$\mathrm{F}=\left(0.59958 \mathrm{~F}_{1}+0.26119 \mathrm{~F}_{2}\right) / 0.86078$

$\mathrm{F}_{1}=0.054 \mathrm{X}_{1}+0.042 \mathrm{X}_{2}+0.155 \mathrm{X}_{3}+0.169 \mathrm{X}_{4}+0.152 \mathrm{X}_{5}+0.145 \mathrm{X}$ ${ }_{6}+0.012 \mathrm{X}_{7}+0.156 \mathrm{X}_{8}+0.152 \mathrm{X}_{9}+0.159 \mathrm{X}_{10}$ 
$\mathrm{F}_{2}=0.366 \mathrm{X}_{1}+0.0 .368 \mathrm{X}_{2}-0.023 \mathrm{X}_{3}+0.03 \mathrm{X}_{4}+0.102 \mathrm{X}_{5}$ $+0.073 \mathrm{X}_{6}+0.333 \mathrm{X}_{7}-0.028 \mathrm{X}_{8}-0.034 \mathrm{X}_{9}-0.017 \mathrm{X}_{10}$
The above formulas are used to calculate the scores, comprehensive scores and rankings of 21 cities in Guangdong Province, as shown in Table 5.

Table 5 Logistics performance of characteristic agricultural products in 21 cities in Guangdong Province

\begin{tabular}{|c|c|c|c|c|c|c|c|c|c|c|c|c|c|}
\hline \multirow{2}{*}{ City } & \multicolumn{2}{|c|}{$\mathrm{F} 1$} & \multicolumn{2}{|c|}{ F2 } & \multicolumn{2}{|r|}{$\mathrm{F}$} & \multirow{2}{*}{ City } & \multicolumn{2}{|c|}{$\mathrm{F} 1$} & \multicolumn{2}{|c|}{$\mathrm{F} 2$} & \multicolumn{2}{|c|}{$\mathrm{F}$} \\
\hline & Score & Ranking & Score & Ranking & Score & Ranking & & Score & Ranking & Score & Ranking & Score & Ranking \\
\hline Guangzhou & 3.383 & 1 & 0.688 & 5 & 2.565 & 1 & Jiangmen & -0.294 & 10 & 0.005 & 10 & -0.203 & 12 \\
\hline Shenzhen & 2.18 & 2 & -1.306 & 21 & 1.122 & 2 & Yangjiang & -0.509 & 17 & 0.016 & 9 & -0.35 & 13 \\
\hline Zhanjiang & 0.095 & 5 & 2.955 & 1 & 0.963 & 3 & Heyuan & -0.514 & 18 & -0.017 & 11 & -0.363 & 14 \\
\hline Maoming & -0.189 & 6 & 1.434 & 2 & 0.303 & 4 & Shantou & -0.261 & 9 & -0.622 & 14 & -0.371 & 15 \\
\hline Dongguan & 0.664 & 3 & -1.043 & 19 & 0.146 & 5 & Jieyang & -0.452 & 15 & -0.348 & 12 & -0.421 & 16 \\
\hline Qingyuan & -0.314 & 11 & 0.93 & 3 & 0.064 & 6 & Zhongshan & -0.21 & 7 & -0.99 & 18 & -0.447 & 17 \\
\hline Foshan & 0.339 & 4 & -0.636 & 15 & 0.044 & 7 & Zhuhai & -0.499 & 16 & -1.047 & 20 & -0.665 & 18 \\
\hline Zhaoqing & -0.315 & 12 & 0.762 & 4 & 0.012 & 8 & Shanwei & -0.751 & 21 & -0.566 & 13 & -0.695 & 19 \\
\hline Meizhou & -0.355 & 13 & 0.527 & 6 & -0.088 & 9 & Chaozhou & -0.666 & 19 & -0.792 & 17 & -0.704 & 20 \\
\hline Huizhou & -0.252 & 8 & 0.18 & 8 & -0.121 & 10 & Yunfu & -0.707 & 20 & -0.707 & 16 & -0.707 & 21 \\
\hline Shaoguan & -0.372 & 14 & 0.27 & 7 & -0.177 & 11 & & & & & & & \\
\hline
\end{tabular}

It can be found in the table that the logistics performance of Guangzhou, Shenzhen, Zhanjiang, Maoming and other regions is higher, while that of Zhuhai, Shanwei, Yunfu, Chaozhou and other regions is lower.Because different regions have different characteristics in production, demand and logistics development of characteristic agricultural products, it is necessary to continue to cluster the logistics level of characteristic agricultural products in each region and select the logistics development mode suitable for the characteristics of each region.

\subsubsection{Cluster analysis}

The cluster average method of the system cluster method was used to cluster 21 cities in Guangdong Province by spss19.0. According to the classification results, the development level of characteristic agricultural products logistics in 21 cities of Guangdong Province is divided into 5 categories.

The first category is Guangzhou. as the capital of Guangdong Province, which belongs to the economic leading city of Guangdong Province, with good economic foundation, Internet popularization, large population scale, strong production and consumption of characteristic agricultural products, good logistics scale and infrastructure, and a balanced supply and demand city.

The second category is Shenzhen, which belongs to a super metropolis. It has a good economic foundation and strong consumer spending power.It has a strong demand for characteristic agricultural products. The city has basically realized urbanization with very little agricultural production. It is a typical demand city for characteristic agricultural products. The required characteristic agricultural products are all dependent on the introduction from other regions, with obvious advantages in logistics scale and development environment.

The third category includes Maoming and Zhanjiang, which belong to two very important cities in western Guangdong and the node city of the maritime Silk Road, with good foundation of featured agricultural products. The first batch of special agricultural products in Guangdong province accounted for 6 in Maoming and 3 in Zhanjiang, and the aquaculture industry in these two cities is developed. All kinds of special tropical agricultural products and aquatic products are exported to domestic and foreign markets, belonging to the cities with strong supply capacity and logistics capacity of special agricultural products

The fourth category of cities includes Shaoguan, Heyuan, Meizhou, Huizhou, Shanwei, Jiangmen, Yangjiang, Zhaoqing, Qingyuan, Jieyang, and Yunfu.Except for Huizhou, they are all underdeveloped areas in Guangdong Province. Such areas have weak economic foundations and weak logistics development, but all belong to traditional agricultural markets. They have large output of characteristic agricultural products, limited domestic demand, and are mainly for export. The key area for poverty alleviation and rural revitalization, but the current weak logistics capacity has hindered the development of local specialty agricultural products to a certain extent. How to make the local specialty agricultural products circulate quickly, effectively and with high quality has become an urgent problem.

The fifth category includes Zhuhai, Shantou, Foshan, Dongguan, and Zhongshan.These five cities Shantou belong to the Special Economic Zone, and the other four cities are important economic cities in the Pearl River 
Delta. They are all cities with relatively weak primary industry and weak production capacity of characteristic agricultural products, which belong to the demandoriented cities of characteristic agricultural products. However, the current logistics capacity of characteristic agricultural products is not strong.

\section{THE CHOICE OF THE DEVELOPMENT MODE OF GUNDONGS'S CHARACTERISTIC AGRICULTURAL PRODUCT LOGISTICS UNDER THE “INTERNET +” BACKGROUND}

Through the evaluation and cluster analysis of the logistics capacity of the characteristic agricultural products in Guangdong Province, it is found that there are great differences in the economic development, industrial development and the development of the characteristic agricultural products in Guangdong Province.Therefore, according to its own characteristics, it is necessary to choose a local agricultural product logistics development model that is suitable for local characteristics, and to optimize and innovate these logistics models according to the current development characteristics of the Internet.

Guangzhou and Shenzhen are the leading economic cities in Guangdong Province, with high Internet penetration rate and strong strength of large supermarket chains, The supply chain partner alliance mode can be selected to reduce the intermediate links, which can not only ensure the rapid flow of characteristic agricultural products, but also reduce logistics costs, increase farmers' income, reduce sales prices and benefit the people.As a city without agriculture, Shenzhen can take the initiative to connect with the underdeveloped areas such as Heyuan and Shaoguan, and sign contracts with local specialty agricultural product bases to form supply chain partnerships. The less-developed areas are responsible for production. Shenzhen's agricultural enterprises Responsible for distribution processing, logistics, sales, information management, etc., and become a leader in specialty agricultural products.

Maoming and Zhanjiang have strong production and logistics capabilities.There are large-scale agricultural production bases and agricultural product processing bases in the region,As a local agricultural leader, this type of enterprise can adopt a self-operated logistics model, which can better control the upstream and downstream enterprises in the supply chain, can better build a brand of specialty agricultural products, realize the integration of production and marketing of characteristic agricultural products, and obtain better economic benefits .In the process of implementation,the "Internet+" self-built logistics information network can be used to include other weak agricultural product producers in the region into the network, helping them to achieve the production, distribution and sales of characteristic agricultural products and play their leading role.

Shaoguan, Heyuan, Meizhou, Huizhou, Shanwei, Jiangmen, Yangjiang, Zhaoqing, Qingyuan, Jieyang and
Yunfu are underdeveloped regions. The production of characteristic agricultural products belongs to small-scale decentralized production and operation.At present, it mainly depends on the wholesale market logistics model.But we need to change the traditional wholesale market logistics model, which has many problems, such as information opacity, many transaction links, high transaction costs, more logistics costs, and large product losses, It is necessary to improve the traditional wholesale market logistics model, introduce "Internet + " into this model, establish a characteristic agricultural product information network led by the wholesale market, and include all producers, wholesalers, and logistics enterprises in the information network to achieve production Real-time docking of sales, purchase, logistics.hrough the information network, the producers can understand the market, make targeted production, and realize rapid sales; the wholesalers can know where there is commodity, and realize rapid purchase; the logistics enterprises can know where there is freight, and realize rapid flow of products; in order to reduce product loss and circulation cycle, reduce transaction cost and logistics cost, and ensure farmers' income.

Zhuhai, Shantou, Foshan, Dongguan and Zhongshan have a good economic foundation. They are characteristic cities with demand for agricultural products and can vigorously develop the third-party logistics mode.Through the professional third logistics of agricultural products, the rapid flow of characteristic agricultural products can be realized and reach every consumer.Capable companies can encourage the development of a supply chain partner alliance model, reduce intermediate links, reduce transaction costs and logistics costs, and promote the development of local characteristic agricultural product flows.

\section{CONCLUSION}

This paper analyzes the characteristics of agricultural products logistics, through the analysis of the actual data of 21 cities in Guangdong Province, and gives suggestions for the development of logistics mode.According to the current development trend of the Internet, in view of the problems existing in the current logistics model, the logistics model is optimized, and it is hoped that the logistics development model suitable for the region can be selected according to the local conditions to promote the development of regional characteristic agricultural economy.

\section{ACKNOWLEDGMENT}

This work was supported by Guangdong Provincial Department of Education's 2018 Young University Innovative Talents Project (2018GWQNCX122) and Heyuan Vocational 
and Technical College Key Philosophy and Social Science Project (2018SK01)

\section{REFERENCES}

[1] Department of agriculture and rural areas of Guangdong Province.Notice on Identifying Guangdong's Special Agricultural Product Advantage Zones (First Batch) [EB/OL].2019.7.30. http://dara.gd.gov.cn/tzgg2272/content/post_2574557.ht $\mathrm{ml}$

[2] Allegra V,Bellia C.The Logistics of Direct Sales:New Approaches ofthe EU[J].Italian Journal of Food Science.2014,26(4):443-450.

[3] Xun Jin, Wang Yahui, Fan Xuemei.Information monitoring system for cold chain logistics status of fresh agricultural products $[\mathrm{J}]$. Journal of Jilin University (Engineering \& Technology Edition),2013,43(6):1 707-1 713.

[4] Guangdong Provincial Statistics Bureau, Guangdong Provincial Survey Team of the National Bureau of Statistics. Guangdong Statistical Yearbook 2018. [EB/OL].

http://stats.gd.gov.cn/gdtjnj/content/post_2639622.html

[5] Fang Kai, Zhong Shengbao. Efficiency analysis of cold chain logistics enterprises in China based on green supply chain $[\mathrm{J}]$. Agricultural Technology \& Economy, 2014, (6): 45-55. 